\title{
Las estelas monolíticas ibéricas. Una aproximación a su problemática
}

\author{
Arturo Oliver Folx
}

\section{RESUMEN}

El estudio de las estelas ibéricas, salvo excepcionales ocasiones, practicamente se ha realizado desde el punto de vista lingüístico y epigráfico. Por eso, hemos considerado oportuno, plantear la problemática que ofrece este tipo de documentación desde el punto de vista arqueológico dentro del contexto social de la Cultura Ibérica.

\section{NOMBRES CLAVE}

Estelas, ibérico.

\section{ABSTRACT}

Iberian Steles studies have been doing generally from the point of view of Language and Epigraphy aspect. So, we are introducing the problem of this type of documentation from an archaeological aspect, inside social context of Iberian Culture.

\section{KEY WORDS}

Stele, iberian.

* Servicio de Investigaciones Arqueológicas y Prehistoricas. Diputación de Castellón. Apartado de Correos, 316. 12080. Castellón. 
En las líneas siguientes, intentaremos ofrecer una aproximación a la problemática que presentan las estelas monolíticas de la Cultura Ibérica, es decir las realizadas con un bloque de piedra generalmente de forma paralelepipédica, sobre el que se efectúa una inscultura o un epígrafe.

Aunque en los últimos años la bibliografía sobre las estelas ibéricas ha sido relativamente abundante, debido a la identificación de los monumentos funerarios tipo turriforme, pilares-estelas y de los túmulos escalonados en la zona del sudeste, ésta ha ido dirigida a identificar y caracterizar estos monumentos arquitectónicos mucho más complejos, los cuales contrastan con la sencillez de las estelas monolíticas, que responden a una situación social completamente diferente.

Las estelas monolíticas aunque se conocen ya en la bibliografía a partir de los eruditos del siglo XVII, y son mencionadas como tales en los diferentes tratados epigráficos y de recopilación de antigüedades, no han recibido un tratamiento de análisis que las aglutine en su conjunto y que plantee los diferentes problemas que presentan. La existencia de epígrafes sobre ellas, ha hecho que el estudio de éstos reste importancia a la totalidad de la pieza. Las estelas epigráficas han sido analizadas siempre practicamente en su contexto lingüístico-epigráfico, tan solo encontramos estudios de conjunto de estelas en el caso del grupo del Bajo Aragón, pues, generalmente, no ofrece epígrafe alguno. Por tanto, el estado de la cuestión referente a las estelas va dirigido sustancialmente a su problemática lingüística. Este planteamiento nos ha llevado a un desconocimiento del valor que tendría este tipo de monumento funerario dentro de la sociedad ibérica. Tan solo en un par de ocasiones se ha querido ofrecer una síntesis de algunos de los diferentes tipos de estelas ibéricas (Lucas et al., 1991; Oliver, 1994).

Esta falta de un estudio amplio dentro del contexto social ibérico, viene dado en parte, por las características del hallazgo de estas piezas, la mayoria encontradas de forma casual, reaprovechadas en la construcción, y sin contexto arqueológico alguno, por lo menos aparente. No obstante, la situación en que se encuentra el estado de la cuestión sobre la Cultura lbérica, debido a los avances realizados en los últimos años, especialmente en el aspecto referente a la estructuración social de ésta, creo que nos permite abordar el tema de las estelas monolíticas desde un punto de vista diferente y con unas premisas más seguras. Siendo para ello necesario tratar el conjunto de estelas en su totalidad, aunque diferenciando los diversos grupos de estelas monolíticos que se pueden identificar. 


\section{PRECEDENTES}

La existencia de estelas monolíticas en la Península lbérica la podemos rastrear desde épocas prehistóricas, como vemos en los denominados "ídolos dolménicos" fechados en la época del Bronce, como es el caso del guijarro estela de Hernán Pérez (Almagro Basch, 1972; Almagro Gorbea, 1993), aunque en otras zonas europeas podemos encontrar la presencia de estelas ya en época neolítica (Voruz, 1992). La tradición continúa durante toda la época del bronce, llegando al bronce final en donde alcanza su momento de mayor aceptación, como podemos ver en las conocidas estelas del sudoeste peninsular (Galán, 1993). Este conjunto de estelas parece ser que recibe una fuerte influencia mediterránea especialmente fenicia (Almagro Basch, 1974; Almagro Gorbea, 1977), aunque hay autores que indican unas procedencias griegas (Bendala, 1977; 1979; 1983).

Otras estelas peninsulares del Bronce serían el caso de la de Preixana (Maluquer, 1971; Almagro Basch, 1974), y las de Alberite (Castiella, 1977). Durante el Bronce final del noreste podemos identificar también una serie de "estelas" que son complementos de monumentos funerarios más complejos, como es el caso de los túmulos; estas "estelas" las localizamos en el Coll del Moro de Gandesa (Rafel, 1989; 1990), así como en las «estelas» antropomorfas de la necrópolis tumular de Mequinenza (Royo, 1994).

Todo ello, nos lleva a unos claros precedentes de estelas funerarias monolíticas que podemos rastrear a lo largo de la prehistoria peninsular, y que tienen sus paralelos en el resto de la Europa occidental.

\section{LAS ESTELAS IBÉRICAS}

Como hemos podido comprobar en épocas preibéricas, existe una serie de monumentos funerarios formados por estelas de forma paralelepipédica que parecen responder a un interés de destacar la importancia social que tendría el difunto, por lo tanto, estamos ante el exponente de una jerarquización social que podemos identificar desde la Edad del Bronce, aunque el significado iconográfico y por tanto el valor religioso y social de la pieza varió durante las diferentes épocas prehistóricas, ya que podemos considerar que las estelas representan tanto a una divinidad o al difunto, ello es uno de los puntos más discutidos en el tema; pero lo que sí está claro es que en el Bronce final aparece una heroización del difunto, una personalización, ya que en este momento se le representa, generalmente es un guerrero. 
Ya dentro de la etapa protohistórica y concretamente de la Cultura Ibérica, el uso de la estela monolítica sigue desde un primer momento y a lo largo de toda esta cultura protohistórica peninsular.

Dentro del amplio conjunto de estelas identificadas correspondientes a una cronología ibérica, podemos establecer y diferenciar los siguientes grupos:

- Estelas antropomorfas.

- Estelas epigráficas no decoradas.

- Estelas epigráficas decoradas.

- Estelas del Bajo Aragón.

- Estelas sin grafismos.

\section{Estelas antropoformas}

Estas estelas monolíticas se han localizado en Espejo (Córdoba) (Lucas et al., 1991), Altea (Alicante) (Morote, 1981), Ares (Castellón) (Ballester, 1942); también se ha considerado dentro de este grupo, una estela que se encontraba en el Museo de Córdoba (Santos, 1959), pero a nuestro entender, $y$ al igual que ya se ha indicado en otros trabajos (Lenerz, 1993), ésta corresponde posiblemente a un pilar céltico con cabezas cortadas. Se caracteriza este grupo por su forma paralelepipédica en donde se ha adaptado el cuerpo insculpido, faltando en todas las estelas la cabeza, debido posiblemente a que el estrechamiento del cuello hace que sea la parte más vulnerable de la pieza. El predominio de la forma paralelepipédica sobre la antropomorfa, nos hace diferenciar estas estelas de lo que son las esculturas funerarias.

Destaquemos en ellas el estilo hierático y geométrico en la representación de los adornos y vestiduras de los personajes representados. Es frecuente la presencia de los cinturones, como habíamos visto en otras estelas prehistóricas peninsulares a partir del estilo III de Almagro (Almagro, 1977), es el caso de las de Hernán Pérez. Para algunos autores en la representación del cinturón se simboliza el alto status del personaje (AA.VV., $1992,61)$. También podemos rastrear desde época prehistórica las representaciones de los collares o torques, que ya se encuentran en los guijarros estelas. Otro de los elementos que aparece en estas estelas, exceptuando la de Ares, es la presencia de las manos, que podría indicar el poder y la acción (AA.VV. 1992: 61). La situación de las manos es la misma que vemos también en los guijarros estelas del Bronce, así como 
en otras estelas protohistóricas de Europa, como son las lumigianas que se inician en el III milenio y perduran hasta el siglo II a. de C., las daunias, con una cronología más restringida, siglo VII-VI a. de J.C., y también las ilirias y las picentinas, y muy similar a la de las representaciones de personajes oferentes ibéricos, pero en esta ocasión sin la ofrenda entre las manos.

En cuanto a los personajes representados, tenemos que tan solo la estela de Altea es un hombre, concretamente, debido al armamento que lleva, un guerrero. Destaca en ella la presencia de un cuchillo afalcatado en la parte de delante, entre las dos manos, ya que normalmente estos cuchillos se sujetaban en el tahalí de la espada, o directamente en la cintura. Podríamos estar en este caso ante la ofrenda del arma. El ofrecimiento del armamento, no sólo en los hombres si no incluso en las mujeres, como vemos en la Dama de Baza, es frecuente en el mundo funerario ibérico. Debemos de indicar no obstante, que las representaciones de puñales en la parte delantera ya se encuentran en las estelas del Bronce. Las tres estelas restantes corresponden a representaciones femeninas, lo que es muy frecuente en la plástica funeraria ibérica, como vemos en la mencionada Dama de Baza y en la de Elche. También es común en la figuras oferentes de los santuarios. De nuevo, con estas representaciones femeninas, se sigue planteando la misma cuestión que en las piezas prehistóricas, ¿estamos ante una representación del finado o ante una diosa?

Estas estelas posiblemente se situarían sobre el lugar del enterramiento, y se sujetarian por medio de su parte inferior, como podemos comprobar perfectamente por la pieza de Ares. El tipo de enterramiento al que se encontraría asociado es difícil de conocer, ya que en ninguna ocasión se han podido encontrar con ellos. Tal vez, se relacionarian con algún túmulo, ocupando la misma posición de los pilares estelas o las esculturas que vemos en la necrópolis de los Villares (Albacete) (Blánquez, 1991), en donde se han localizado esculturas de jinetes, de un guerrero y otra de un varón sin armas, que se colocarían directamente encima del túmulo escalonado de un enterramiento. Bien es verdad, que la estela de Altea se encontraba relacionada con una necrópolis de simple loculo, pero no con un enterramiento concreto, ya que estratigráficamente no presenta conexión alguna.

El no presentar estas cuatro estelas una relación directa con ningún enterramiento, puede llevarnos a plantear si verdaderamente las insculturas cumplen una función funeraria, o serían exvotos de oferentes. Ya que, ¿por qué no podemos considerar también la dama de El Tollo de Cehegín como una estela funeraria? (Ruano, 1987), pues practicamente es una 
forma paralelepipédica sobre la que se sitúa la cabeza, y está en acto de ofrenda, concretamente un espejo.

Funcional, simbólica y socialmente estas insculturas tienen el mismo papel que ofrece la escultura funeraria, exaltar la posición social de los miembros de los grupos de poder, al igual que veiamos en épocas prehistóricas, concretamente en la estela de Altea la de un militar, lo que nos indica la importancia de este estamento social.

Los paralelos formales con las estelas antropomorfas prehistóricas nos hacen pensar que las ibéricas son una tradición de las existentes ya en la Edad del Bronce. La falta de una estelas funerarias en las necrópolis fenicias del sur peninsular, o en las posibles necrópolis griegas de Ampurias, podría indicarnos que estamos ante una tradición local más que ante una influencia externa, que indudablemente sí la tenemos con las estelas pilares ibéricas, aunque debemos de reconocer que tampoco existen pilares estelas griegas en la Península.

El problema que presentan estas estelas se centra en relacionarlas con el mundo funerario, y no con ritos de ofrendas; $y$ en la presencia de un porcentaje elevado de mujeres, lo cual nos llevaría a considerar la importancia de la mujer en el mundo ibérico, a no ser que sean representaciones de sacerdotisas, de allí la categoría social de la representada, o que verdaderamente estemos ante la imagen de una diosa. La diferencia de estilo entre las estelas aquí tratadas y las esculturas funerarias, es otro de los problemas que nos plantea este grupo de piezas, cómo podemos interpretar esta diferencia, ¿es una problemática meramente estilistica, o hay una relación social, geográfica o cronológica?.

El hallazgo de estas piezas fuera de un contexto no nos permiten ofrecer unas dataciones concretas a las mismas, tan solo en el caso de Altea la Vella, el conjunto de materiales localizados junto a la estela, e incluso el elemento del puñal, nos pueden ofrecer una cronología del siglo $\mathrm{VI}$ a. de J.C. Para algunos autores estas estelas se darían a lo largo de toda la cultura ibérica (Lucas, et al., 1991). Las estelas antropomorfas tendrán su perduración en época hispanorromana.

\section{Estelas epigráficas no decoradas}

Las estelas epigráficas no decoradas fueron objeto por nuestra parte de un pequeño estudio de conjunto que presentamos en el $V$ "Congreso Internacional de Estelas Funerarias" celebrado en Soria el año 1993 (Oliver,1994). Debido a la cantidad, y posiblemente por la similitud que 
ofrecen con las estelas latinas, y por ser las que se conocen desde hace más tiempo, pues se mencionan ya en la bibliografía del siglo XVII, siempre se han considerado como el prototipo de la estela funeraria ibérica.

Es el grupo más numeroso de todas las estelas ibéricas superando el número de treinta.

El material escriturario sobre el que se ha realizado es la caliza o la arenisca triásica. Estas estelas presentan una preparación muy poco cuidada, con una tendencia al formato rectangular, que a lo sumo ofrece un redondeamiento en la parte superior. El texto epigráfico se compone de una a siete líneas, y en algunas ocasiones se encuentra enmarcado dentro de una cartela.

La dispersión geográfica de las estelas epigráficas no decoradas va desde Vic, como punto más septentrional, hasta Sagunto como límite meridional. Las estelas situadas más al oeste son la de Vic, Algimia de Almonacid, Iglesuela del Cid y la de Sinarcas, entre 40 y $80 \mathrm{~km}$ de la costa en línea recta. Podemos comprobar también que el $87,50 \%$ se sitúan al sur del río Ebro, y que el gran porcentaje de ellas, casi la mitad, un $43,75 \%$ proceden de la población de Sagunto. Mención especial debido al lugar de su hallazgo, es la localizada en Ibiza, de momento un caso único de epigrafía ibérica fuera de la región ibérica, y que no sabemos a que se debe (García Bellido, 1948; Vallejo, 1948).

La inexistencia de un contexto arqueológico en el lugar del hallazgo de las lápidas, no nos permite tener datos sobre su cronología, por lo que para ofrecer una datación a las inscripciones debemos basarnos en las características intrínsecas de estos documentos. La estructuración del texto en las estelas ibéricas según J. Unterman, es una imitación de las latinas, incluso aparecen formulas completas que son copiadas (Unterman, 1984, 117). Además, parece ser que hay formaciones en genitivo copiadas del latín (Siles, 1986; Velaza, 1993). Presenta pues, en general una relación formal con las latinas (Mayer, Velaza, 1993; Velaza, 1993). Los epígrafes al tener arqueológicamente cierta relación con yacimientos pertenecientes a época hispanorromana o del ibérico tardío, consideramos que podrían ofrecer una cronología del siglo I a. de J.C. y de la centuria siguiente, debido especialmente a la estructuración y al tipo de concepción de la estela, muy influenciada tal y como se ha indicado, por el mundo romano.

El hallazgo de epigrafes ibéricos en villae, nos denuncia una perduración del sustrato cultural indigena durante la plena romanización. El sincretismo entre el latín y el ibérico lo podemos ver en la existencia de nombres latinos en epigrafes ibéricos, y nombres ibéricos con grafismos latinos, lo que podemos comprobar durante el siglo I a. de J.C. y el siguiente. 


\section{Estelas epigráficas decoradas}

Otra unidad de estelas ibéricas la componen las que presentan un texto acompañado de una decoración con simbología astral, ya que su iconografía se basa en discos o ruedas radiales y lunas, claros elementos funerarios, y relacionados con la transmigración de las almas (Iglesias, 1983, 96), o del lugar de estancia de los muertos (Blázquez, 1983, 269; Cumont, 1942, 117; Abasolo et al., 1975, 69). La iconografía de la luna podría estar en conexión con una deidad indígena (Hatt, 1970). La luna dentro del contexto funerario representaría el ciclo de la vida, siendo la menguante, que es la representada en las estelas, el simbolismo de la decrepitud. Los ciclos lunares podrían representar la continuidad de la vida. De estas estelas tenemos tres ejemplares, uno proveniente de Fraga (Fita, 1894), un segundo de Badalona (Guitart, 1976) y por último el más oriental proviene de Barcelona (Hübner, 1893; Albertini, 1911-1912). Esta iconografía entroncará con la de las estelas hispanorromanas de gran parte del territorio hispano, lo cual nos da un elemento más para considerarlas cronológicamente dentro del periodo hispanorromano. No obstante, el problema que hemos visto en las anteriores estelas lo encontramos también aquí, la falta de un contexto arqueológico del hallazgo, ya que ninguna de ellas se ha localizado en una excavación arqueológica.

La iconografía astral representada en estas estelas puede proceder por una parte de la misma influencia romana, o también, de una tradición indígena que vemos en gran parte de Europa y del Mediterráneo, de la cual recibe influencias la propia epigrafía romana, y que encontramos especialmente en la parte norte peninsular. Para F. Marco la iconografía astral es autóctona, proveniente del substrato hallstáttico, es decir, habría una superposición de símbolos, los alóctonos y los autóctonos. Para J.M. Blázquez las representaciones astrales se relacionan con el simbolismo del toro funerario (Blázquez, 1983, 247), lo que enlazaria el tradicional simbolismo ibérico de este animal con una nueva tendencia iconográfica.

La rueda con radios curvos representaría al sol (Marco, 1978), aunque también se ha relacionado con otros simbolismos, es el caso del trueno (Mañanes et al., 1992, 300), o las puertas celestes (Jullien, 1910; Schober, 1923; Nagy, 1941; Cumont,1942); para otros serian los brazos de Atlante (Abasolo et al., 1975). Las rosáceas para algunos autores pueden ser una representación solar (Mañanes, 1992, 300; Marco, 1978), así como la svástica que encontramos en la estela de Badalona. Un claro simbolismo de tradición romana son los delfines que existen en la estela de Barcelona. Estos animales representan el paso de las almas a la isla afortunada, de nuevo la transmigración del alma del difunto. En la estela de Badalona 
hay tres puntas de lanza, simbolismo sobre el que volveremos más adelante, pero remarquemos la presencia de esta iconografía típica de las estelas del Bajo Aragón en esta zona.

La presencia de un nombre latino escrito con caracteres ibéricos concretamente en la de Badalona, nos muestra aún más la influencia del mundo romano sobre estas estelas.

\section{Estelas del bajo Aragón}

Desde el inicio de la arqueología en la comarca aragonesa del Bajo Aragón se ha identificado un grupo de estelas, en su mayoría anepigráficas, pues tan solo en tres ocasiones presenta escritura, concretamente grafismos ibéricos (Martín-Bueno, Pellicer, 1979-1980; Atrián, 1979), que ha sido objeto de trabajos de conjunto (Fernández, 1951; Marco, 1978). Estas estelas presentan una rica iconografía en donde se representan especialmente lanzas hincadas, manos amputadas y jinetes. La zona geográfica que ocupan las estelas se sitúa entre Caspe y Valderrobles. La cronología parece ser que es baja, ya que se supone una fechación entre el siglo II y I a. de J.C. (Marco, 1976, 90), no obstante, hemos de indicar que estas piezas también presentan la problemática que hemos visto en el resto de las estelas, una falta de contexto arqueológico que pueda datar la pieza con toda seguridad.

El simbolismo de este grupo de estelas es puramente indígena, pues por una parte tenemos las lanzas, que se relacionan desde los estudios de A. Schulten (Schulten, 1912) tomando como base un texto de Aristóteles (Política, VII.2-5), con los enemigos abatidos, de la misma idea son otros autores como J. Cabré, F. Marco, F. Quesada (Cabré, 1915-20; Quesada, 1994.). Significado similar tendrían las manos amputadas, tomando también como base las fuentes clásicas (Estrabón, III,3,6; Diodoro,XIII,57,3). Para F. Marco las puntas de lanza significarían una heroización del difunto (Marcos, 1976, 33-34); significado similar para F. Marco tendrian los posibles escudos que aparecen en estelas clunienses, y que también presenta una de las estelas de Caspe, descartando la posibilidad de que indiquen el número de enemigos o el número de batallas vencidas, idea sustentada por otros autores (García Bellido, 1949, 371). Mientras, M. Martín y M. Pellicer opinan que correspondería a un simple elemento decorativo (Martín, Pellicer, 1979,1980). Otro elemento iconográfico, las aves devorando los cuerpos, se relaciona también con una cita de un autor clásico (Silio Itálico, Pun. III, 342-343), y lo vemos igualmente en la iconografía indígena, como es el caso de la cerámica de Numancia. De nuevo, 
nos encontramos con un simbolismo de transmigración de las almas, ya que las aves carroñeras remontarian las almas de los difuntos al cielo.

La presencia de jinetes y caballos se encuadra dentro de la iconografía indígena, lo cual queda patente en la numismática ibérica. Este simbolismo, o bien puede basarse en la heroización del difunto o en su estatus social, o bien, el caballo puede tener un significado sicopompo, ya que este animal está muy relacionado con el culto solar. No hace falta recordar la existencia de tumbas desde épocas anteriores con caballos y carros. La roseta de la estela de Valderrobles (Atrián, 1979), tal y como hemos indicado más arriba, está relacionada con un simbolismo astral y posiblemente ligada a la tradición astral prerromana.

Tan sólo en la estela de Caspe en que se representa un león, podemos evidenciar cierta influencia procedente del mundo colonial, griego de forma indirecta, y de los pueblos ibéricos de la costa de forma más directa, ya que encontramos sus prototipos en la iconografía zoomorfa, y más concretamente en la escultura zoomorfa procedente de los pilares estelas del sudeste, en donde este animal haría la función de guardián de la tumba. Para M. Martín y M. Pellicer, la presencia de inscripciones sería una influencias romana (Martín, Pellicer, 1979-1980, 419).

La iconografía de estas estelas, tal y como demuestra el armamento representado, nos acerca de nuevo a un grupo social concreto, el estamento militar, como vemos en otros monumentos funerarios ibéricos, ya sean estelas o esculturas.

\section{Estelas sin grafismo}

En la necrópolis de Cabezo Lucero del Guardamar del Segura (Alicante), se citan un par de estelas que son meras lajas preparadas de forma paralelepipédica e hincadas en el suelo, señalando la sepultura. De las dos mencionadas, tan sólo una se encontró in situ y curiosamente indicaba la presencia de una ofrenda. Los excavadores de esta necrópolis apuntan a una identificación de las diferentes tumbas a través de estelas realizadas con materiales perecederos, así como por las estelas del tipo mencionado, y que como es lógico fueron los primeros elementos que se degradaron tras el abandono de la necrópolis (Aranegui, et al., 1993, 39-40).

En el singular enterramiento de inhumación ibérico localizado en el Coll del Moro de Tivissa se indica la posibilidad de que una losa situada sobre las piernas del muerto y que sobresalía ligeramente, fuese "a modo, acaso, de estela anicónica» (Vilaseca, 1953, 36). 


\section{CONSIDERACIONES GENERALES}

El concepto de estela como el monumento funerario más sencillo, la Cultura lbérica parece ser que lo toma de una tradición indígena que podemos remontar a mediados de la Edad del Bronce, con las estelas antropomorfas, las cuales responden a su vez, a una unidad estilística dentro de las estelas de Europa occidental. En el período ibérico aunque en escaso número, estas estelas antropomorfas, podrían perdurar durante todo el segmento cronológico ocupado por esta cultura de la antigüedad peninsular. Aunque la funcionalidad de la estela y su simbolismo de heroización del guerrero en el caso de la encontrada en Altea, parece estar claro dentro del contexto social del momento, al igual que ocurre en otras estelas prehistóricas y protohistóricas europeas, no podemos identificar tan fácilmente las representaciones femeninas, ya que bien pudiéramos estar ante damas oferentes, o ante representaciones de diosas y no de personas más o menos heroizadas. Por otra parte, las insculturas chocan con la perfección estilística y estética de la escultura funeraria ibérica, ¿por qué esta diferencia de calidad artística entre las insculturas de las estelas y las esculturas de los pilares estelas? Indudablemente estas estelas podrian tener una situación dentro de los enterramientos similar a la que tenian las esculturas localizadas en la necrópolis albaceteña de los Villares, serían las indicadoras de la situación del enterramiento.

El momento de mayor apogeo para las estelas ibéricas lo encontramos en un período tardío, concretamente a partir del siglo II a. de J.C., y ello debido a la influencia recibida del mundo latino. Por una parte tenemos las estelas del Bajo Aragón con una tradición iconográfica fuertemente indígena, en donde la heroización del individuo sigue representada a través de la imagen. Mientras tanto, en la costa encontramos un cambio, pues la importancia social se da a través de la escritura, la cual ha tomado la función de la imagen, el epígrafe es un portador de valores eternos (Susini, 1982). Estamos ante un periodo más evolucionado, en donde el control de la escritura nos indica un poder social que ha sustituido al de las armas, este poder del control de la escritura puede estar ligado a un momento de paz, y a un comercio estable. El alfabeto se encuentra en el mismo estamento de prestigio, sino lo ha sustituido, que el armamento. La importancia de la escritura como elemento sagrado, así como algunos elementos iconográficos, y la cronología tardía de las estelas, que podría superar el cambio de era, nos indican la fuerte influencia que la sociedad romana tendría en el mundo ibérico del momento. La existencia de una escritura que está expuesta al público nos denuncia por otra parte una mayor alfabetización de la sociedad, ya que ésta ya no necesita de pictogramas para la comprensión de un mensaje. 
Las estelas al igual que cualquier otro monumento funerario suponen en general la superación de la muerte en el recuerdo de los vivos.

Un problema grave, tal y como ya hemos indicado, es la falta de una relación entre las estelas y las necrópolis o las tumbas, lo que ya expusimos en su dia (Oliver, 1994). Aunque hemos visto que las estelas pilares y tumbas turriformes se encuentran encima de la tumba, no sucede así con las estelas monolíticas. En otra ocasión ya planteamos que siendo la finalidad de la estela una exaltación personal, no es obligatorio por tanto que ésta se encuentre en el lugar de la tumba. Cabría la posibilidad también, que las estelas limitasen un espacio determinado como era el caso de los horoi griegos, que indicaban el área de los temenos.

La problemática de la señalización de las tumbas especialmente en las necrópolis de gran parte de Valencia y de Cataluña está abierta, ya que en ellas, exceptuando los enterramientos tumulares, como es el caso del Coll del Moro de Gandesa, no se han localizado muestras de señales indicativas en la superficie; tal vez se indicarían con un elemento perecedero, como podrían ser las estelas de madera. Por otra parte la distribución de las tumbas dentro de la necrópolis, como la del Mas de Mussols, Miames, la Solivella, no presentan una distribución ordenada. Tan solo en el caso de la necrópolis del Puig de la Nau, parece ser que exista un cierto ordenamiento de las tumbas, aunque justamente es la que menor número de enterramientos ofrece, por lo que no se puede asegurar esta situación.

La estela ibérica desaparece indudablemente por la influencia de la tradición romana, las estelas funerarias con epígrafe latino sustituirán a las ibéricas, ya sean epigráficas o no.

\section{BIBLIOGRAFIA}

AA.VV., 1992: La sociedad ibérica a través de la imagen. Ministerio de Cultura. Madrid.

Abasolo, J.A., Albertos Firmat, M.L., Elorza, J.C., 1975: Los monumentos funerarios de época romana en forma de casa de la región de Poma de la Sal (Bureba, Burgos). Burgos.

AlBERTINI, E., 1911-1912: Sculptures antiques du Conventus Tarraconenses. Anuari de l'Institut d'Estudis Catalans, 4. Barcelona.

Almagro BASCH, M., 1972: Los idolos y la estela decorada de Hernan Pérez (Cáceres) y el idolo estela de Tabuyo del Monte (León). Trabajos de Prehistoria, 29. 83-124. Madrid.

Almagro BASCH, M., 1974: Nuevas estelas decoradas de la Península ibérica. Miscelánea Arqueológica II. XXV Aniversario de los Cursos Internacionales de Prehistoria y Arqueología en Ampurias (1947-1971): 5-39. Barcelona.

Almagro Gorbea, M., 1977: El Bronce final y el periodo orientalizante en Extremadura. Biblioteca Praehistorica Hispana, XIV. Madrid.

Almagro Gorbea, M., 1988: Origen y significado de la escultura ibérica. Escultura lbérica. Revista de Arqueologia: 58-59. Madrid.

Almagro GorbeA, M., 1992: Los intercambios culturales entre Aragón y el litoral mediterráneo durante el Bronce final. Actas del coloquio Aragón/litoral mediterráneo. Intercambios culturales durante la prehistoria: 633-658. Zaragoza. 
Almagro Gorbea, M., 1992a: Las necrópolis ibéricas y su contexto mediterráneo. Actas del Congreso de Arqueología Ibérica: las necrópolis, (Madrid, 1991): 37-75. Madrid.

ALmagro GorbeA, M., 1991: Las estelas de guerrero del SW en el marco de las estelas de la Península Ibérica. Actas del Colloque le Monte Bego une montaigne sacrée de l'áge du bronze. Sa place dans le contexte des religions protohistoriques du Bassin Mediterranéen. Aix en Provence.

Almagro Gorbea, M., 1993: Les steles anthropomorphes de la Péninsule lbérique. Actas del 115 Congrès National des Sociétés Savants. Les representations humaines du neolithique a l'áge du fer (Avignon, 1990): 123-139. Paris.

aranegui, C., Jodin, A., Llobregat, E., Roulllaro, P., Uroz, J., 1993: La nécropole ibérique de Cabezo Lucero. Guardamar del Segura, Alicante. Madrid-Alicante.

ATRIÁN JORDÁN, P., 1979: El yacimiento de Torre Gachero (Valderrobres) y las estelas ibéricas del Museo de Teruel. Teruel, 61-62. 157-178. Teruel.

BAllester TORMO, I., 1942: Estela ibérica labrada. La labor del SIP y su Museo en los años 1935 a 1939: 129-132. Valencia.

BENDALA, M., 1977: Notas sobre las estelas decoradas del suroeste y los orígenes de Tartessos. Habis, 8: 177-207. Sevilla.

BENDALA, M., 1979: Las más antiguas navegaciones griegas a España y el origen de Tartessos. Archivo Español de Arqueología, 52. 33-39. Madrid. Archivo Español de Arqueología, 52. 33-39. Madrid.
BENDALA, M., 1983: Entorno al instrumento musical de la estela de Luna (Zaragoza). Homenaje
a Martín Almagro, $t$. It: 141-146. Madrid.

BLANQUEZ PÉREZ, J.J., 1992: Las necrópolis ibéricas en el sureste de la Meseta. Actas del Congreso de Arqueología Ibérica: las necrópolis (Madrid, 1991): 235-278, Madrid (1991).

BLÁZOUEZ J.M 1983: Religiones prerromanas. Primitivas religiones Ibéricas II. Madrid.

CABRE, J., (1915-1920): Estèles ibèriques ornamentades del Baix Aragó, Anuari de l'institut d'Estudis Catalans, Vl: 629. Barcelona.

CAStIELLA, A., 1977: La Edad del Hierro en Navarra y Rioja. Pamplona.

CUMONT, F., 1942: Recherches sur le symbolisme funeraire des Romains. Paris.

Fernandez Fuster, L., 1951: Las estelas ibéricas del Bajo Aragón. Seminario de Arte Aragones, III: 55 y ss. Zaragoza.

FITA, F. 1894: Fraga, inscripciones romanas e ibéricas. Boletín de la Real Academia de la Historia, XXV: 257-305. Madrid.

Galán Domingo, E., 1993: Estelas, paisaje y territorio en el Bronce Final del suroeste de la Península Ibérica. Madrid.

Garcia Bellido, A., 1948: Inscripción ibérica de Ibiza. Archivo Español de Arqueología, 21: 284-285. Madrid.

GARCIA y BELLIDO, A., 1949: Esculturas romanas de España y Portugal. Madrid.

Guitart DuRÁN, J., 1976: Baetulo. Topografía, arqueología. Urbanismo e historia. Badalona.

Guitart durán, J. Pera Isern, J., Mayer Olive, M., Velaza, J., 1996: Noticia preliminar sobre una inscripción ibérica encontrada en Guissona (Lleida). La Hispania Prerromana: actas del $V I$ Coloquio sobre Lenguas y Culturas Prerromanas de la Península lbérica (Coimbra, 13-15, octubre, 1994): 148-161. Coimbra.

HATT, J.J., 1970: Les croyances funerarires des gallo-romains d'après la décoration des tombes. Revue Archéologique de l'Est et du Centre-est, 21.

HÜBner, A., 1893: Monumenta linguae ibericae. Berlín. IgLESIAS GIL, J.M., 1976: Epigrafía cántabra. Estereometho, des. Revue Archéologique de l'Est et JULLIEN, C., 1910: Chronique
dU Centre-Est, XII: 89-91.

LAGRAND, CH., 1981: Les stèles cultuelles protohistoriques du Pèque (Drôme). Revue Archéologique de l'Est et du Centre-Est,32. 121-130.

LENERZ DE WILDE, M., 1993: Sculptures anthropomorphes du 2 âge du fer sur la Peninsule lberique. Actas del 115 Congres National des Sociétés Savants. Les representations humaines du neolithique a l'age du fer (Avignon, 1990): 123-139. Paris.

Lucas, M.R., Ruano, E., Serrano, J., 1991: Escultura ibérica de Espejo (Córdoba): hipótesis sobre su funcionalidad. Espacio, Tiempo y Forma, serie II, Ha. Antigua, IV: 297-318. Madrid.

Maluquer, J., 1971: La estela de la Edad del Bronce de Preixana. Homenaje a J.E. Uranga: 475. Pamplona. 
Mañanes, I., Hernández Guerra, L., Jiménez Furundarena, A., 1992: Un conjunto epigráfico inédito de Medina del Campo (Valladolid). Hispania Antiqua, XVI: 273-308. Valladolid.

Marco Simón, F., 1976: Nuevas estelas ibéricas de Alcañiz (Teruel). Pyrenae, 12: 73-90. Barcelona.

MARCO SiMÓN, F., 1978: Las estelas decoradas de los conventos caesaraugustano y cluniense. Caesaraugusta, 43-44. Zaragoza.

Martín Bueno, M., Pellicer Catalá, M., 1979-1980: Nuevas estelas procedentes de Caspe (Zaragoza). Habis, 10-11: 401-420. Sevilla.

MAYER, M., VELAZA, J., 1993: Epigrafía ibérica sobre soportes tipicamente romanos. Lengua y cultura en la Hispania prerromana. Actas del $V$ Coloquio sobre lenguas y culturas prerromanas de la Península lbérica (Colonia, 1989): 667-682. Salamanca.

Morote, G., 1981: Una estela de guerrero con espada de antenas en la necrópolis ibérica de Altea la Vella. Archivo de Prehistoria Levantina, XVl: 417-446. Valencia.

NAGY, L., 1941: Les symbolisme astraux sur les monuments funéraires de la population indigène de la Pannonia. Laureae Aquicensis, II (Dissertationes pannonicae, ser. 2: II).

OLIVER FOIX, A.: 1994: Aproximación a la problemática de las estelas epigráficas funerarias ibéricas no decoradas. Actas del $V$ Congreso Internacional de Estelas Funerarias, (Soria 1993), vol. I: 107-116. Soria.

PUIG I CADAFALCH, J.,1934: L'arquitectura romana a Catalunya. Barcelona.

Quesada SANz, F., 1994: Lanzas hincadas, Aristóteles y las estelas del Bajo Aragón. Actas del $\checkmark$ Congreso Internacional de Estelas Funerarias (Soria, 1993), vol I: 361-170. Soria

Royo GuILlÉn, I., 1994: Estelas y cipos funerarios en la necrópolis tumular de los Castellets de Mequinenza. Actas del V Congreso Internacional de Estelas Funerarias (Soria, 1993), vol I: 117-134. Soria.

Rafel Fontanals, N., 1989: La necropolis del Coll del Moro de Gandesa. Les estructures funèraries. Tarragona.

Rafel fontanals, N., Hernández Herrero, G., 1990: Sistemas y prácticas funerarias en la necrópolis del Coll del Moro (Gandesa, Terra Alta). Zephyrus, XLII: 339-348. Salamanca.

RuANo Ruiz, E., 1987: La escultura humana de piedra en el mundo ibérico. Madrid.

Santos Gener, S., 1950: Guía del Museo Arqueológico Provincial de Córdoba. Madrid.

SCHOBER, A., 1923: Die römischen grabsteine von noricum und Pannonien. Soderschriften der osterreichischen-Archäelogischen Instituts in Wien, $X$. Viena.

SCHULTEN, A.,1912: Les points de lance représentées sur les stèles funéraires. Bulletin Hispanique, XIV: 196 y ss.

SILES, J., 1986: Sobre la epigrafía ibérica. Actas de la Reunión sobre Epigrafía hispánica de época romano-republicana (Zaragoza, 1983): Zaragoza.

Unterman, J., 1984: Inscripciones sepulcrales ibéricas. Cuadernos de Prehistoria y Arqueología Castellonenses, 10:111-119. Castellón.

UnTERMAN, J., 1990: Monumenta Linguarum Hispanicarum, III. Die iberischen inschriften aus Spanien. Wiesbaden.

VALLEJO, J., 1994: Sobre la lápida ibérica anterior: ¿más rastros ilirios en España?. Archivo Español de Arqueología, 21: 286-288. Madrid.

VelAZA, J., 1993: Una nueva lápida ibérica procedente de Civit (Tarragona). Pyrenae, 24: 59165. Barcelona.

Vilaseca Anguera, S., 1953: Coll del Moro. Yacimiento posthallstáttico. Estudios lbéricos, 1. Valencia.

Voruz, J.L., 1992: Hommes et dieux du Neólithique. Les statues menhirs d'Yuerdon. Annuaire de la Société Suisse de Préhistoire et d'Archéologie, 75: 37-64. Basel. 